\title{
FIBER GLASS WR600 COMPOSITE JOINTING STRENGTH
}

\author{
Istyawan Priyahamsara ${ }^{1}$, Ahmad Kurnia Mas Pratama ${ }^{2}$ \\ Jurusan Teknik Dirgantara-Sekolah Tinggi Teknologi Adisutjipto \\ istyawanpriyahapsara@gmail.com
}

\begin{abstract}
The test is carried out only to obtain the value of the joint strength or the joining strength against the tensile test. From the data obtained, the average value obtained on the specimens using the adhesive bonding method is an angle of 0 18.355. Angle 30 27,665 angle 45 23,354 angle 60 18,781. This can be seen from the failure mode the connection or joining is experiencing. The adhesive bonding method has a large difference in the strength value between the angle 0, 30 angle, 45 angle, 60 angle The average value of the tensile strength that the specimen has is the angle 018.355 . Angle 30 27,665 angle 45 23,354 angle 6018,781 the largest is angle 30 is 37,665 and the lowest angle is 018,35 .
\end{abstract}

Keyword: adhesive, resin,sudut dan fraksi volume

\section{Latar Belakang}

Revolusi Industri 4.0 merupakan fenomena yang mengkolaborasikan teknologi cyber dan teknologi otomatisasi. Konsep penerapannya berpusat pada konsep otomatisasi yang dilakukan oleh teknologi tanpa memerlukan tenaga kerja manusia dalam proses pengaplikasiannya. Hal tersebut tentunya menambah nilai efisiensi pada suatu lingkungan kerja di mana manajemen waktu dianggap sebagai sesuatu yang vital dan sangat dibutuhkan oleh para pemain industry[1] [2]. Selain itu, manajemen waktu yang baik secara eksponensial akan berdampak pada kualitas tenaga kerja dan biaya produksi dengan semakin berkembangnya teknologi industri dalam bidang otomotif dan dirgantara material komposit memiliki keunggulan yaitu ringan kuat tidak mudah korosi dan mudah di bentuk dan beralih menggunakan material komposit untuk dijadikan salah satu bahan alternatif yang dapat digunakan untuk pembuatan bodibodi kendaraan seperti mobil, pesawat bahkan kereta api.Penggunaan material komposit pada suatu pesawat terbang tidak selalu dalam suatu bagian utuh, penggunaannya juga dapat berupa sub-part atau bagian-bagian kecil yang kemudian digabungkan satu sama lain. Proses penggabungan antar material komposit tersebut dapat dilakukan dengan berbagai metode yaitu metode riveting, bolted joint, adhesive bonding, hybrid dan sebagainya. Metode yang paling sering digunakan pada umumnya adalah metode adhesive bonding [4][5] .Proses penggabungan antar material komposit memiliki kelebihan dan kekurangan pada setiap metodenya, mulai dari efisiensi waktu yang digunakan pada proses penggabungan tersebut, total berat penggabungan tersebut sampai dengan kemampuan atau ketahanan pada penggabungan tersebut. Proses penggabungan material komposit menggunakan metode adhesive bonding adalah penggabungan secara chemical yang menggunakan perekat berbahan kimia [6]

\section{Metodologi Penelitian}

Dalam metode ini penulis mengunakan beberapa metode yang digunakan yaitu

a. Metode Wawancara, yaitu metode mengumpulkan data dan informasi terkait dengan penelitian yang akan dilakukan dengan cara bertanya langsung kepada 
narasumber yang berkompeten dalam bidang komposit fiber glass baik itu dosen, laboran tempat melakukan penelitian dan lain sebagainya.

b. Metode Studi Pustakan, yaitu metode pengumpulan data dengan membaca buku, artikel atau jurnal penelitian yang telah dilakukan sebelumnya.

c. Persiapan Alat, Bahan, dan Specimen Uji, yaitu mempersiapkan segala sesuatu untuk mendukung proses penelitian. Pada penelitian ini penulis menggunakan material Komposit Fiber Glass, dan Epoxy Resin sebagai bahan utama dalam penelitian [7].

d. Proses adhesive bonding adalah proses penggabungan antara 2 plat. Dalam penelitian ini penulis melakukan proses bonding di rumah dan dikerjakan oleh penulis.

e. Pengujian yang dilakukan adalah uji tarik, tujuan dari dilakukannya pengujian tarik adalah untuk mengetahui kekuatan sambungan adhesive bonding dan dilakukan di rumah dan meminjam alat di La. Nurtaio kampus Sekolah Tinggi Teknologi Adisutjipto.

Analisis dan pembahasan berisi data asli hasil pengujian specimen yang menggunakan adhesive bonding. Data dari hasil pengujian dianalisis sehingga menghasilkan hipotesa maupun analisa dari hasil pengujian yang kemudia dijadikan sebagai pembahasan dan kesimpulan.

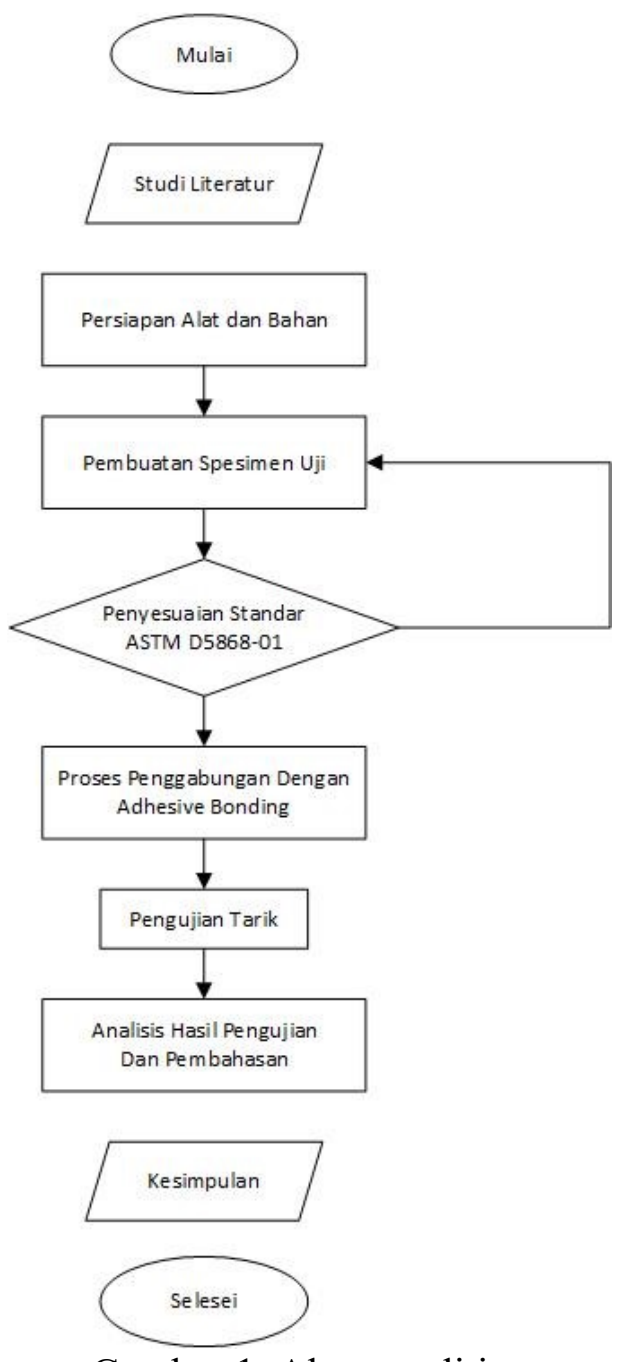

Gambar 1. Alur penelitian 


\section{Hasil dan Pembahasan}

\section{Proses Perihtungan Dan Pembuatan Specimen Komposi}

Proses pertama yang dilakukan dalam melakukan penelitian adalah pembuatan spesimen komposit sesuai standard ASTM D3039-01 bolted joint Adhesion Fiber Reinforced Plastic (FRP) Bonding dengan dimensi spesimen $100 \mathrm{~mm} \times 25.4 \mathrm{~mm} \times$ 2,6mm kemudian dilakukan penggabungan variasi sudut 0304560 dan dilakukan pengujian. Di setiap sudut Spesimen dibuat dengan 4 jenis sudut dan 4 kali pengujian dengan megunakan 4 layer fiber glass. Jumlah spesimen yang dibuat adalah 16 pesimen. Adapun langkah perhitungan fraksi volume sebagai berikut:

a. Menimbang massa fiber glass dengan ukuran disesuaikan dengancetakan yang sudah dibuat dengan dimensi $310 \mathrm{~mm} \times 185 \mathrm{~mm}$ yaitu $35 \mathrm{gr} / \mathrm{lembar}$.

b. Menentukan volume komposit yang dimensinya disesuaikan dengan cetakan yang dibuat.

$$
\begin{aligned}
\text { Volume komposit } & =\mathrm{P} \times \mathrm{L} \times \mathrm{T} \\
& =250 \mathrm{~mm} \times 250 \mathrm{~mm} \times 2,6 \mathrm{~mm} \\
& =162.500 \mathrm{~mm}^{3} \\
& =162 \mathrm{~mm}^{3}
\end{aligned}
$$

c. Volume fiberglass yang menggunakan 4 lembar

$$
\begin{array}{ll}
\text { Massa total fiber glass } & =4 \times \text { massa fiberglass } \\
& =4 \times 35 \mathrm{gr} \\
& =140 \mathrm{gr} \\
& =\frac{\text { mass a fiber glass }}{\text { massa jenis fiber glass }} \\
& =\frac{140 \mathrm{gr}}{2,632 \mathrm{gr} / \mathrm{cm}^{3}} \\
& =53,1914 \mathrm{~cm}^{3}
\end{array}
$$

d. Menentukan fraksi volume fiber glass pada komposit

Fraksi volume fiber

$$
\begin{aligned}
& =\frac{\text { volume fiber glass }}{\text { volume komposit }} \times 100 \% \\
& =\frac{53,1914}{162} \times 100 \% \\
& =32,8341 \%
\end{aligned}
$$

e. Menentukan faktor volume matriks pada komposit

$$
\begin{array}{ll}
\text { Volume matriks } & =\mathrm{v} . \text { Komposit }-\mathrm{v} . \text { Fiber glass } \\
& =162-53,1914 \\
& =108,8086 \mathrm{~cm}^{3} \\
& =\frac{\text { volume matrix }}{\text { volume komposit }} \times 100 \% \\
& =\frac{108,8086}{162} \times 100 \% \\
& =67,1650
\end{array}
$$

f. Menentukan kebutuhan epoxy dan hardener perbandingan epoxy dan hardener adalah 2:1

$$
\begin{array}{ll}
\text { Volume epoxy } & =\frac{2}{3} \times 108,8086=72,5390 \mathrm{~cm}^{3} \\
\text { Kebutuhan epoxy } & =\mathrm{v} . \text { Epoxy } \times \text { massa jenis epoy } \\
= & 72,590 \times 1,2 \\
& =87,0468 \mathrm{gr} \\
& =\frac{1}{3} \times 108,8086=36,2695 \mathrm{~cm}^{3} \\
\text { Volume hardener } & =\mathrm{v} . \text { Hardener } \times \text { massa jenis hardener } \\
\text { Kebutuhan hardener } & =36,2695 \times 0,97 \\
& =35,181415 \mathrm{gr}
\end{array}
$$


Proses pembuatan spesimen komposit menggunakan metode, yaitu menggunakan metode hand lay up Penggunaan metode hand lay up selama proses pembatan dikarenakan metode tersebut cukup mudah digunakan dan menggunakan alat yang cukup mudah dicari Spesimen komposit yang dibuat searah dengan rajut fiber glass yang digunakan. Adapun langkah - langkah pembuatan spesimen komposit sebagai berikut:

a. Menyiapkan alat dan bahan yang akan digunakan selama proses pembuatan spesimen komposit.

b. Melakukan pemotongan terhadap fiber glass yang ukurannya disesuaikan dengan ukuran cetakan yaitu $250 \mathrm{~mm}$ x $250 \mathrm{~mm}$. Pemotongan dilakukan dengan gunting

c. Menyiapkan dan membersihkan cetakan yang ingin digunakan. Cetakan tersebut berupa kaca dengan tebal alas $8 \mathrm{~mm}$

d. Memberikan molding wax terhadap permukaan cetakan yang berguna untuk memudahkan pelepasan spesimen terhadap cetakan menggunakan kuas secara merata disetiap permukaan.

e. Melakukan pengukuran massa menggunakan neraca digital pada setiap lembar fiber glass yang sudah dipotong sesuai dengan ukuran cetakan, yaitu dengan ukuran $250 \mathrm{~mm}$ x $250 \mathrm{~mm}$ memiliki massa 35gr. Pengukuran massa ini dibutuhkan guna mengetahui fraksi volume komposit yang akan dibuat.

Melakukan pencampuran resin dan hardener. Fraksi volume yang digunakan Spesimen menggunakan 4 lembar fiber glass dengan fraksi volume 67,1658\% matriks dan 32,8341\% fiber dengan berat resin 87,0468gr dan hardener $35,181415 \mathrm{gr}$.

f. Melakukan metode hand lay up, dimana fiber glass ditaruh kedalam cetakan dan di sesuai arah rajut fiber glass kemudian dituangkan cairan resin yang sudah diolah kemudian diratakan menggunakan scrapper secara bertahap setiap lembar fiber.

g Melakukan press dan pengerigan Mengunakan galon pengeringan selamakurang lebih 8 jam. merupakan salah satu metode pembuatan komposit.

h. Melakukan pelepasan spesimen komposit dari cetakan apabila pengeringan menggunakan proses press sudah selesai.

i. Melakukan pemotongan specimen komposit yang disesuaikan standar ASTM D-3039-01 dengan ukuran $250 \mathrm{~mm}$ x 250mm x 2,6mm. Pemotongan menggunakan alat bantu berupa tape paper ukuran standar spesimen untuk mempermudah dan mengurangi kesalahan dalam menyesuaikan ukuran.

j. $\quad$ Melakukan proses finishing yang berupa membersihkan specimen dari berbagai benda asing dan melakukan koreksi ukuran sehingga mendapatkan hasil yang maksimal.

Proses penggabungan dengan Spesimen komposit yang sudah berhasil dibuat kemudian dilakukan penggabungan atau joint dengan menggunakan metode adhesive bonding.

Metode adhesive bonding adalah metode penggabungan secara chemical menggunakan perekat kimia berupa resin epoxy dan hardener. Waktu rata-rata yang dibutuhkan selama proses adhesive bonding adalah 360 menit atau 6 jam. Adapun langkah melakukan proses adhesive bonding sebagai berikut:

a. Menyiapkan dan membersihkan cetakan yang akan digunakan.

b. Melakukan pemberian wax pada cetakan agar mempermudah proses pelepasan spesimen. 
c. Melakukan pencampuran, dan pengadukan bahan perekat resin epoxy dan hardemer.

d. Melakukan perekatan dengan memberikan perekat epoxy di area spesimen yang sudah diberikan tanda kemudian dilakukan penempelan secara perlahan dan merata. Untuk lebih jelas dapat melihat gambar 4,20

e. Proses pegeringan spesimen yg sudah di resin yg sudah di sesuaikan variasi sudut

Dari hasil pengujian tarik menggunakan metode adhesive bonding didapatkan nilai maximum force (kgf) dan ketahanan rekat terhadap geseran (Mpa). Specimen komposit yang dilakukan pengujian adalah spesimen komposit dengan variasi sudut 0304560 dengan menggunakan metode adhesive bonding sebanyak 4 spesimen (A, B C D) dengan 4 kali pengujian masing sudut, Hasil pengujian dapat dilihat dengan tabel berikut.

Tabel 1. Hasil pengujian sambungan dengan sudut 0

\begin{tabular}{|c|c|c|c|}
\hline No & Spesimen & $\begin{array}{c}\text { ketahanan rekat terhadap geseran } \\
\text { (Mpa) }\end{array}$ & maximum force (Kgf) \\
\hline 1 & A & 20,432 & 208.350 \\
\hline 2 & B & 18,800 & 191.704 \\
\hline 3 & C & 15,382 & 156.848 \\
\hline 4 & D & 18,804 & 191.749 \\
\hline \multicolumn{2}{|c|}{ rata-rata } & 18,355 & 187.163 \\
\hline
\end{tabular}

Table 2. Hasil pengujian sambungan dengan sudut 30

\begin{tabular}{|c|c|c|c|}
\hline No & spesimen & $\begin{array}{c}\text { ketahanan rekat terhadap geseran } \\
\text { (Mpa) }\end{array}$ & maximum force (Kgf) \\
\hline 1 & A & 32,139 & 327.729 \\
\hline 2 & B & 24,698 & 251.853 \\
\hline 3 & C & 24,940 & 254.316 \\
\hline 4 & D & 28,883 & 294.525 \\
\hline \multicolumn{2}{|c|}{ rata-rata } & 27,665 & 282.106 \\
\hline
\end{tabular}

Table 3. Hasil pengujian sambungan dengan sudut 45

\begin{tabular}{|c|c|c|c|}
\hline No & Spesimen & $\begin{array}{c}\text { ketahanan rekat terhadap geseran } \\
(\mathbf{M p a})\end{array}$ & maximum force (Kgf) \\
\hline 1 & A & 19,940 & 203.334 \\
\hline 2 & B & 22,708 & 231.561 \\
\hline 3 & C & 28,021 & 285.734 \\
\hline 4 & D & 22,747 & 231.957 \\
\hline \multicolumn{2}{|c|}{ rata-rata } & 23,354 & 238.147 \\
\hline
\end{tabular}


Table 4. Hasil pegujian sambunngan dengan sudut 60

\begin{tabular}{|c|c|c|c|}
\hline No & Spesimen & $\begin{array}{c}\text { ketahanan rekat terhadap geseran } \\
\text { (Mpa) }\end{array}$ & maximum force (Kgf) \\
\hline 1 & A & 23,990 & 244.268 \\
\hline 2 & B & 20,805 & 212.152 \\
\hline 3 & C & 15,456 & 157.611 \\
\hline 4 & D & 14,868 & 151.611 \\
\hline \multicolumn{2}{|c|}{ rata-rata } & 18,781 & 191.411 \\
\hline
\end{tabular}

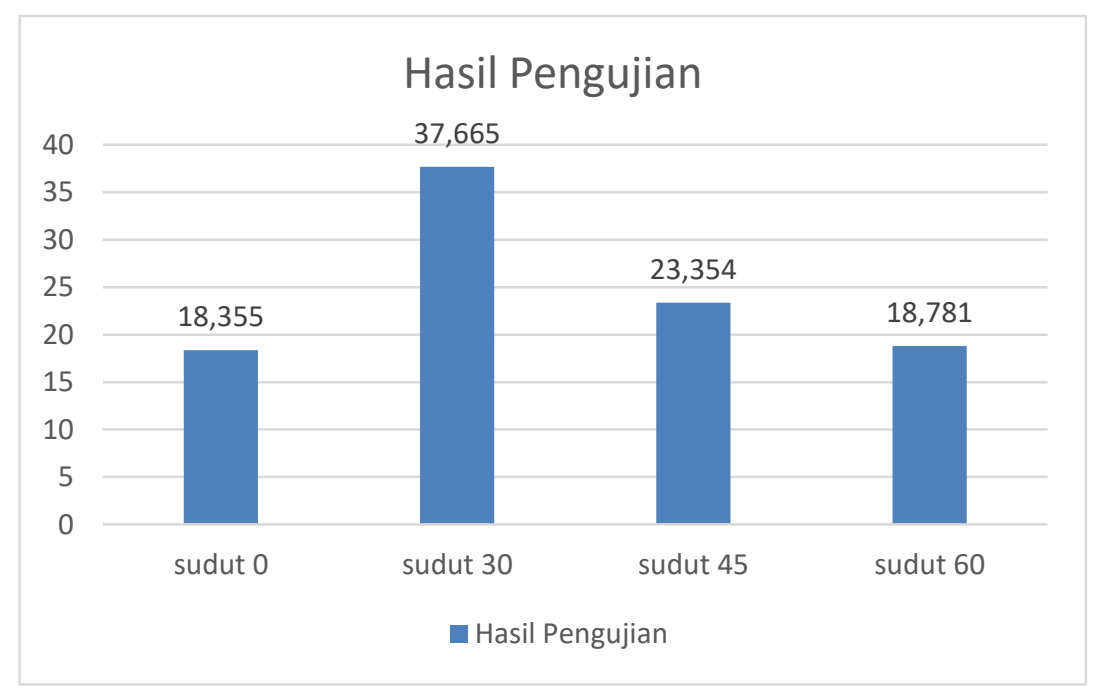

Gambar 2. grafik hasil pengujian

Pengujian yang dilakukan hanya untuk mendapatkan nilai kekuatan sambungan atau kekuatan penggabungan terhadap uji tarik. Dari data yang diperoleh, nilai ratarata yang didapatkan pada spesimen yang menggunakan metode adhesive bonding adalah sudut 0 18,355. Sudut 30 27,665 sudut 45 23,354 sudut 60 18,781

Hal ini dapat diliat dari mode kegagalan yang dialami oleh sambungan atau penggabungan tersebut. Metode adhesive bonding memiliki perbedaan besar nilai kekuatan antara spesimen sudut 0 , sudut 30 ,sudut 45 , sudut 60 Nilai rata-rata kekuatan tarik yang dimiliki oleh spesimen adalah sudut 0 18,355. Sudut 3027,665 sudut 4523,354 sudut 6018,781 yang terbesar ialah sudut 30 sebesar 37,665 dan yg terendah sudut 018,355

\section{KESIMPULAN}

Proses pembuatan komposit terbagi menjadi beberapa tahap pokok yaitu cetakan, melakukan perhitungan fraksi volume dan pencampuran resin, melakukan proses hand lay up, dan melakukan proses penggabungan metode adhesive bonding juga terbagi menjadi beberapa tahap pokok yaitu menyiapkan cetakan, melakukan proses perekatan pada spesimen dan menunggu proses pengeringan perekat sampai selesai proses ini memerlukan pengerjaan kurang lebih 6 jam.Kekuatan sambungan metode adhesive bonding penulis membuat 4 variasi sudut dan masing"sudut di lakukan 4 kali percobaan untuk perbandingan dan sudut dan melakukan 4 lembar dan sudut nya di sesuaikan dengan sudut 0,30,45,60 ini dikarekan metode adhesive bonding menggunakan perekat resin epoxy, bahan yang juga digunakan sebagai resin pada komposit. Sehingga perekat epoxy ini mampu menyatu dengan baik oleh permukaan komposit dan menghasilkan sambungan yang lebih kuat dan dari semua 
sudut tersebut sudut 30 yg paling kuat Dari semua pengujian tersebut sudut 30 yg kuat karna sdah di lakukan pengujian sebanyak 4 kali dan hasil yg paling kuat di sudut 30

\section{Daftar Pustaka}

[1] Brilian Indra Wibowo,2018. Analisis Proses Penggabugan Komposit Mengunakan Adhesive Bonding Beserta kekuatanya Terhadap Uji Tarik, Sekolah Tinggi Teknologi Adisutjipto.

[2] Mercy, Lilly. 2015. Joint Strenght Analysis of Single Lap Joint in Glass Fiber Composite Material. Sathyabama University

[3] Sugiyanto. 2012. Optimasi Sambungan Kekuatan Serat Gelas. Universitas Sebelas Maret

[4] Dillingham, Dr. Giles. 2017. Fundamentals of Adhesive Bonding of Composite Materials. Aerodef Manufacturing.

[5] Hoke, Michael J. 2010. Abaris Training Inc: Adhesive Bonding of Composites. Abaris Inc

[6] Solmaz, M. Yavus. 2017. Effect of Riveting On The Joint Strenght of Adhesively Bonded Double Lap Joints. Anadolu University

[7] https://www.assemblymag.com/articles/90348-aerospace-fastening-in-the21 st- century diakses pada tanggal 12 November 2018 jam 20.00 WIB 